\title{
Research article \\ Impact of quality of life between old age homes and family households in geriatric population
}

\author{
Anju Shaju Areeckal ${ }^{1}$, Nayanatara Arunkumar ${ }^{2}$, Sheila R. Pai ${ }^{3}$ \\ ${ }^{1}$ Assistant Professor, Department of Physiology, Government Medical College, Thrissur, Kerala, India \\ ${ }^{2}$ Associate Professor, Department of Physiology, Kasturba Medical College, Mangalore, Manipal Academy of Higher \\ Education, Manipal, Karnataka. India \\ ${ }^{3}$ Former Professor, Department of Physiology, Kasturba Medical College, Mangalore, Manipal Academy of Higher Education, \\ Manipal, Karnataka. India
}

(Received: September $2020 \quad$ Revised: May $2021 \quad$ Accepted: June 2021)

Corresponding author: Anju Shaju Areeckal. Email: anjushaju@gmail.com

\begin{abstract}
Introduction and Aim: Life satisfaction is a key aspect of psycho-social study of aging. Social relationships and involvement in activities are key protective factors in maintaining cognitive and functional ability in elderly. The aim of this study is to compare the quality of life (1) among the elderly people living in old age homes and those living with their family, (2) among elderly men and women in Mangalore.
\end{abstract}

Materials and Methods: Study group consists of 160 elderly subjects above the age of 60 years, selected from oldage homes and urban families in Mangalore. The quality of life is assessed using the questionnaires from the World Health Organization Quality of Life (WHOQOL).

Results: The elderly persons living with their family had a better social relationship and social participation than those living at old age homes $(p<0.001)$. The elderly at old age homes had a better personal and intimate relationship than those living with their family $(\mathrm{p}<0.001)$. The elderly men had a better social relationship compared to elderly women $(p<0.05)$. The social participation and intimate relationship was not significantly different for elderly men and women.

Conclusion: Lack of support from family degrades quality of life of elderly. The elderly who experiences social isolation and loneliness are at a greater risk for morbidity, depression and cognitive decline. Hence, it is the responsibility of every individual to work towards the improvement of quality of life in the elderly population.

Keywords: Quality of life; elderly; old-age home; family.

\section{INTRODUCTION}

A ging is an inevitable natural biological process. The advancement of medical science, technology and socio-economic conditions in the recent past has led to increased lifespan of humans. However, geriatric care has been overlooked in the recent decades (1).

The changing living habits of the young generation is a cause of concern and stress for the elderly and has led to increased isolation and deterioration of social relationships. The youth is exploring new social identities and economic independence within and outside the family. This may degrade the sense of duty and care of the youth towards their older family members. Apart from the decline in the traditional sense of responsibility, there is no adequate social security for the elderly. Modernization of the country has caused non-organize societies to be individualized. The elderly people, being economically unproductive, has less prestige and authority over the family and its resources. The traditional joint family system has now diverged to nuclear families, and with the younger generation having less time to care for the older ones, this has given rise to old age homes in India.
Older people above 60 years of age are regarded as geriatric age group, senior citizen of the community or elderly segment of the population. According to Population Census 2011 there are nearly 104 million elderly persons (aged 60 years or above) in India; 53 million females and 51 million males (2). The number of senior citizens has raised from $6.7 \%$ in 1991 to $8.6 \%$ in 2011 ; for males it was marginally lower at $8.2 \%$, while for females it was $9.0 \%$ (3). India ranks second for the highest population of elderly in the world. The United Nations Population Fund report suggests that the number of elderly persons is expected to become 173 million by 2026 (4).

A rapid increase in the elderly population could be due to various factors such as the advanced medical care, improvement in modern medicine, development of diagnostic medical equipment, dramatic rise in life expectancy at birth, better protection by the society, improved living conditions and greater availability of food in the present day which has enhanced the average life span of man. The life expectancy at birth in India during 2020 is 70.4 years (combined); 71.8 years for females as against 69.2 years for males (5). However, the elderly people are vulnerable to physical, mental and social problems. Ageing is 
associated with a variety of problems like poverty, social isolation, widowhood, apparent reduction in family support and dependency towards end of life. An increasing proportion of the elderly people in India points towards a need for greater attention towards them. The age dependency ratio, old (\% of working age population) in India is $9.519 \%$ in 2019 as compared to $7.92 \%$ in 2010 (6).

In this modern era, geriatric care still continues to be a neglected area. According to a report in 2016, $71 \%$ of elderly population resides in rural areas while $29 \%$ is in urban areas (7). Globalization has led to enormous changes in the economic structure. This has weakened the social values and the traditional practice of joint family system. With the modernization of the country, older traditions are replaced by individual, nonorganize societies. Though many elderly people are able to live in their own homes along with their family members with the financial assistance from social and health, a substantial number are residing in care homes or home for the aged. A gradual transition from the usual traditional joint family setup to the smaller nuclear family system has given rise to this concept of institutionalization or old age homes for elderly all over the world. The different reasons attributing for shifting of old people to institutions, according to various studies, were poverty, lack of support from their children, no one to take care of them and loneliness.

In India, there are more than a thousand old age homes, and their number is continuously increasing (8). There are several types of old age homes in India. Old age homes for the destitute who are isolated from society are given the medical care in addition to the basic amenities of food, clothing and shelter. There are paid homes for the aged where care is provided through payment basis. Quality of life refers to the level of satisfaction in life experienced by the senior citizens in physical, social and psychological level of independence. The quality of life among elderly in the living in old age home and family has been an issue of debate since long. An important aspect of psychosocial aging is life satisfaction. The assessment of the quality of life based on life satisfaction is one of the facets of successful aging. Quality of Life can be defined as the perceptions of an individual regarding their life, in terms of the social and cultural aspect and in relation to their goals, expectations and concerns. Research reports that life satisfaction is strongly related to psycho-social health in terms of engagement in physical exercises and social activities and associated morbidities (9).

Ageing creates physical, social and psychological problems not only for an individual but the society they in live too. Various studies have shown that old age people face an emotional void in their lives, irrespective of their economic, marital or educational status (10). An increasing number of elderly people in our country experience deterioration of health and physical ability, loneliness or depression, isolation from family and society and family bereavement. Retirement adds to the increased stress due to negligible income, relocation of homes or a feeling of not being able to contribute to the society. These would lead to depression and loneliness preventing themselves to socially interact and become productive.

Psychologically, most adults 'consider' themselves old before reaching 60 years of age especially the Indian women, probably due to the notion about the motherhood and childcare, which has led to the concept of 'empty nest syndrome' (11). This affects their mental state resulting in depression during the empty nest period. Moreover, a higher proportion of females in 60 years and above category demand an additional focus towards the elderly women. According to several study reports, the elderly individuals feel secured when their physical and psychological needs are met, when appropriate health care is given, when their past achievements have been appreciated, when they experience a sense of belonging, when opportunities are given to strengthen their existing social relationships and to make new social ties and involve in community gathering, when engaged in purposeful activities and above all, when they feel valued by the community they live in.

The quality of life can be assessed using the questionnaires developed by the World Health Organization Quality of Life Group (WHOQOL Group). The WHOQOL-100 Field Trial Version questionnaire, which has been developed after extensive pilot studies, contains 100 questions classified under 24 facets grouped into 6 domains, which allows for a detailed assessment of each facet. Eventually, the WHOQOL-BREF Field Trial Version has been developed so as to provide a quicker assessment of the quality of life. It contains 26 questions grouped into 4 domains (physical, psychological, social and environmental); one item from each of the 24 facets contained in the WHOQOL100 and two items from the Overall Quality of Life and General Health facet (12).

The WHOQOL Group has recently developed the WHOQOL-Old to assess the quality of life in the elderly individuals (13). It consists of 24 questions under six facets (sensory ability, autonomy, past, present and future activities, social participation, death and dying, and intimacy) of four items each. It focuses on the various aspects of the old age as perceived by them. It is a better tool when used in addition to either the WHOQOL-BREF or the WHOQOL-100 questionnaires.

This study aims at comparison of the quality of life (1) among the elderly population living in old age homes and those living with their family, (2) among elderly men and women in Mangalore. 


\section{METHODOLOGY}

The present study was a cross-sectional descriptive study conducted in Mangalore, India. Sample size was calculated with $95 \%$ confidence interval and $90 \%$ power of the study. The subjects were selected by simple random sampling. A total of 160 elders were studied comprising of 80 inmates (40 males and 40 females) of old age homes and 80 (40 males and 40 females) people who are residing with their families. The subjects were studied from selected homes for the aged in the Mangalore City.

The elderly men and women aged 60 years and above, residing in old age homes as well as in home settings within Mangalore Corporation, who were willing to participate in this study and could understand either in English or Kannada were included. The elderly having chronic illness like diabetes mellitus and hypertension were included in this study. The elderly who could not comprehend the language were excluded from the study. The present study was conducted after the approval of ethics Committee. The data were collected from old age home participants after obtaining prior permission from the authorities of the selected old age homes in Mangalore. The data were obtained from the elders residing in their families through a house-tohouse survey. Written informed consent was obtained from the study participants. The respondents were assured the confidentiality of the information provided by them. The assessment of their quality of life in terms of psychosocial health was done using the data obtained from WHOQOL-BREF and WHOQOL-Old questionnaires; either self- evaluated or interviewerbased.

\section{WHOQOL-BREF questionnaire}

The WHOQOL-BREF questionnaire contains 26 Likert scaled questions grouped into 4 domains (physical, psychological, social and environmental). The scores reflect the perception of quality of life of an individual. Higher scores denote better quality of life.

\section{WHOQOL-Old questionnaire}

The WHOQOL-Old questionnaire consists of 24 Likert scaled questions under 6 facets: SAB (sensory ability), AUT (autonomy), PPF (past, present and future activities), SOP (social participation), DAD (death and dying) and INT (intimacy). Each of the facets has 4 items. The 'Sensory Abilities' facet assesses sensory functioning and the consequences of its loss on quality of life. The 'Autonomy' facet denotes the level of independence in decision making in old age. The 'Past, Present, and Future Activities' facet deals with the life satisfaction on various achievements in life and in future, whereas the 'Social Participation' facet involves the individuals' participation in activities of daily living activities at home and in the community. The 'Death and Dying' facet is related to worries about death while the
'Intimacy' facet assesses the personal and intimate relationships.

\section{Statistical analysis}

The data were compiled and categorized based on the place of residence and gender. The statistical analysis was done using SPSS (Statistical Package for Social Sciences) Version 17.0. The data were expressed as Mean \pm SD. The differences between the groups were compared for statistical significance using Student's unpaired t-test.

\section{RESULTS}

Among the entire study population, the mean scores were highest for the environmental domain $(77.68 \pm 20.59)$ and lowest for the social domain (62.88 \pm 21.41$)$, as shown in Fig. 1.

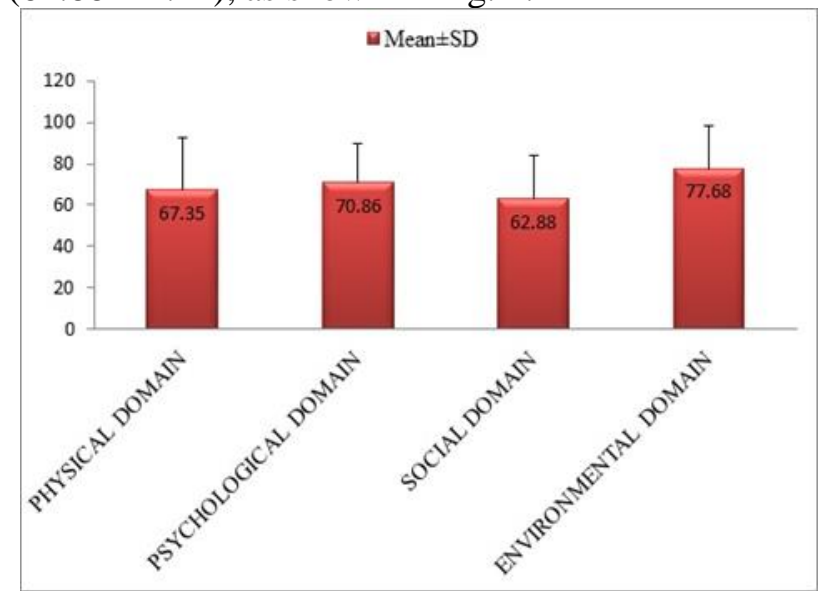

Fig. 1: Scores for the all the domains in WHOQOL-BREF among all the responders in this study. Values are expressed as Mean $\pm \mathrm{SD}$

The comparison between the mean scores among elderly living in old age homes and families showed a statistically significant $(\mathrm{p}<0.001)$ difference in social domain, as given in Table 1 . The elderly living with their family members $(72.81 \pm 20.8)$ had a better social relationship compared to those living in old age homes $(52.94 \pm 17.03)$.

Table 1: Scores for the domains of WHOQOL-BREF questionnaire among the elderly living in old age homes and those living with their families; values are expressed as Mean $\pm \mathrm{SD}$

\begin{tabular}{|c|c|c|c|}
\hline Domains & $\begin{array}{l}\text { Place of } \\
\text { residence }\end{array}$ & Mean \pm SD & t value \\
\hline \multirow{2}{*}{$\begin{array}{l}\text { Psychologic } \\
\text { al domain }\end{array}$} & Old age home & $69.35 \pm 20.8$ & \multirow{2}{*}{$\begin{array}{c}1.01 \\
\mathrm{p}=0.312 \mathrm{~ns}\end{array}$} \\
\hline & Family & $72.36 \pm 16.51$ & \\
\hline \multirow{2}{*}{$\begin{array}{c}\text { Physical } \\
\text { domain }\end{array}$} & Old age home & $64.18 \pm 27.77$ & \multirow{2}{*}{$\begin{array}{c}1.61 \\
\mathrm{p}=\end{array}$} \\
\hline & Family & $70.53 \pm 21.77$ & \\
\hline \multirow{2}{*}{$\begin{array}{c}\text { Social } \\
\text { domain }\end{array}$} & Old age home & $52.94 \pm 17.03$ & \multirow{2}{*}{$\begin{array}{c}6.61 \\
\mathrm{p}=0.001 \\
* * *\end{array}$} \\
\hline & Family & $72.81 \pm 20.8$ & \\
\hline \multirow{2}{*}{$\begin{array}{c}\text { Environmen } \\
\text { tal domain }\end{array}$} & Old age home & $75.3 \pm 22.43$ & \multirow{2}{*}{$\begin{array}{c}1.47 \\
\mathrm{p}= \\
0.144 \mathrm{~ns}\end{array}$} \\
\hline & Family & $80.06 \pm 18.41$ & \\
\hline
\end{tabular}

*** $\mathrm{p}<0.001$ : Elderly living in old age homes versus those living with their family members; ns: not significant. 
While comparing the mean scores between elderly men $(66.84 \pm 19.04)$ and women $(58.91 \pm 22.99)$ as shown in Table 2, there was a statistically significant $(p<0.05)$ difference in the scores for the social domain among elderly men and women. The elderly men had a better social relationship compared to elderly women.

Table 2: Scores for the domains of WHOQOL-BREF questionnaire among the elderly men and women; values are expressed as Mean \pm SD

\begin{tabular}{|c|c|c|c|}
\hline Domains & Gender & Mean \pm SD & t value \\
\hline \multirow{2}{*}{$\begin{array}{c}\text { Physical } \\
\text { domain }\end{array}$} & Male & $65.95 \pm 26.64$ & 0.71 \\
\cline { 2 - 3 } & Female & $68.75 \pm 23.48$ & $\mathrm{p}=0.482 \mathrm{~ns}$ \\
\hline $\begin{array}{c}\text { Psychological } \\
\text { domain }\end{array}$ & Male & $71 \pm 19.88$ & 0.1 \\
\cline { 2 - 3 } & Female & $70.71 \pm 17.74$ & $\mathrm{p}=0.923 \mathrm{~ns}$ \\
\hline Social domain & Male & $66.84 \pm 19.04$ & 2.38 \\
\cline { 2 - 3 } & Female & $58.91 \pm 22.99$ & $\mathrm{p}=0.019^{*}$ \\
\hline \multirow{2}{*}{$\begin{array}{c}\text { Environmenta } \\
\text { 1 domain }\end{array}$} & Male & $79.25 \pm 20.39$ & 0.96 \\
\cline { 2 - 3 } & Female & $76.11 \pm 20.8$ & $\mathrm{p}=0.337 \mathrm{~ns}$ \\
\hline
\end{tabular}

$*$ p<0.05; Elderly men versus elderly women; ns: not significant.

As shown in fig. 2, the mean scores were highest in social participation $(15.56 \pm 3.86)$ facet and lowest for sensory abilities $(8.58 \pm 1.75)$ facet.

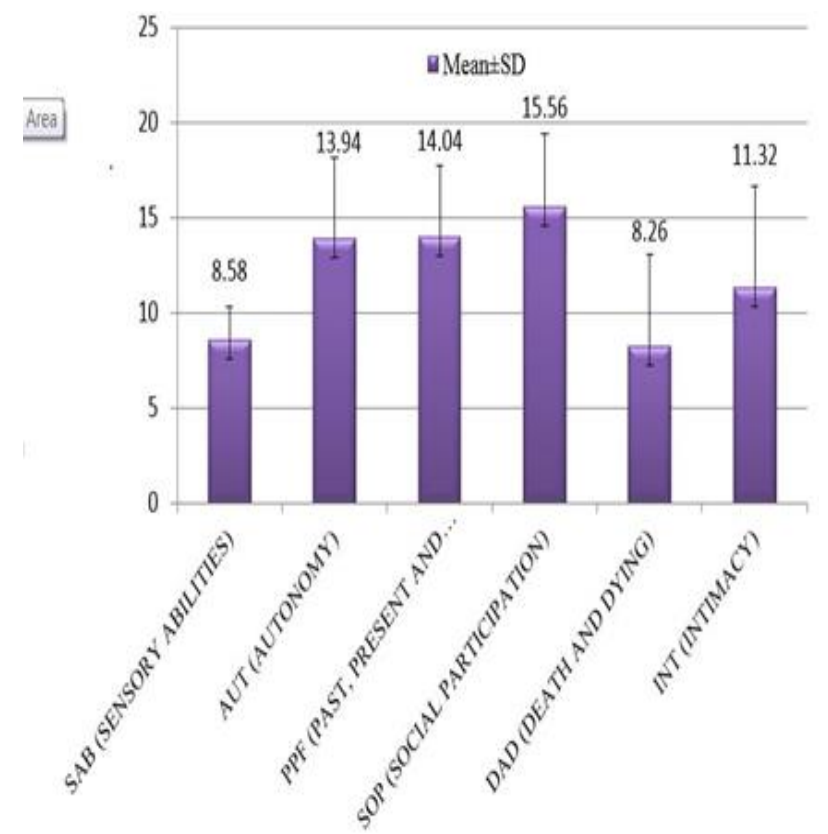

Fig. 2: Scores for the facets of WHOQOL-Old questionnaire among the entire study population; Values are expressed as Mean \pm SD

Table 3 shows the comparison of the scores of the facets between the elderly people living in the old age homes and those living with their family members. The elderly living with their family members $(16.55 \pm 3.379)$ had better social relations $(p<0.001)$ compared to those living in old age homes (14.588 \pm 4.096$)$. In addition, there was a significantly $(\mathrm{p}<0.001)$ better personal relationships and intimacy among those living in old age homes $(12.725 \pm 4.818)$ compared to those living with their family members $(9.925 \pm 5.481)$.
When the elderly men were compared with the elderly women, there was no statistically significant difference between the two groups in any facets, as shown in Table 4.

Table 3: Scores for the facets of WHOQOL-Old questionnaire among the elderly living in old age homes and those living with their family members; values are expressed as Mean $\pm \mathrm{SD}$

\begin{tabular}{|c|c|c|c|}
\hline Facets & Place of residence & Mean \pm SD & t value \\
\hline \multirow{2}{*}{ SAB } & Family & $8.575 \pm 1.613$ & 0.045 \\
\cline { 2 - 4 } & Old age home & $8.588 \pm 1.894$ & $\mathrm{p}=0.964 \mathrm{~ns}$ \\
\hline \multirow{2}{*}{ AUT } & Family & $13.488 \pm 4.186$ & 1.384 \\
\cline { 2 - 4 } & Old age home & $14.400 \pm 4.157$ & $\mathrm{p}=0.168 \mathrm{~ns}$ \\
\hline \multirow{2}{*}{ PPF } & Family & $14.175 \pm 3.880$ & .444 \\
\cline { 2 - 4 } & Old age home & $13.913 \pm 3.594$ & $0.658 \mathrm{~ns}$ \\
\hline \multirow{2}{*}{ SOP } & Family & $16.550 \pm 3.379$ & 3.306 \\
\cline { 2 - 4 } & Old age home & $14.588 \pm 4.096$ & $<0.001 * * *$ \\
\hline \multirow{2}{*}{ DAD } & Family & $8.763 \pm 5.075$ & 1.308 \\
\cline { 2 - 4 } & Old age home & $7.763 \pm 4.582$ & $\mathrm{p}=0.193 \mathrm{~ns}$ \\
\hline \multirow{2}{*}{ INT } & Family & $9.925 \pm 5.481$ & 3.432 \\
\cline { 2 - 4 } & Old age home & $12.725 \pm 4.818$ & $<0.001 * * *$ \\
\hline
\end{tabular}

$* * * \mathrm{p}<0.001$; Elderly living in old age home versus family; ns: not significant.

Table 4: Scores for the facets of WHOQOL-Old questionnaire among the elderly men and women. Values are expressed as Mean \pm SD

\begin{tabular}{|c|c|c|c|}
\hline Facets & Gender & Mean \pm SD & t value \\
\hline \multirow{2}{*}{ SAB } & Male & $8.850 \pm 1.751$ & 1.958 \\
\cline { 2 - 4 } & Female & $8.313 \pm 1.725$ & $\mathrm{p}=.06 \mathrm{~ns}$ \\
\hline \multirow{2}{*}{ AUT } & Male & $13.763 \pm 3.715$ & .547 \\
\cline { 2 - 4 } & Female & $14.125 \pm 4.621$ & $\mathrm{p}=.585 \mathrm{~ns}$ \\
\hline \multirow{2}{*}{ PPF } & Male & $13.900 \pm 3.821$ & .486 \\
\cline { 2 - 4 } & Female & $14.188 \pm 3.656$ & $\mathrm{p}=.627 \mathrm{~ns}$ \\
\hline \multirow{2}{*}{ SOP } & Male & $16.038 \pm 3.612$ & 1.539 \\
\cline { 2 - 4 } & Female & $15.100 \pm 4.080$ & $\mathrm{p}=.127 \mathrm{~ns}$ \\
\hline \multirow{2}{*}{ DAD } & Male & $8.038 \pm 4.713$ & .586 \\
\cline { 2 - 4 } & Female & $8.488 \pm 4.994$ & $\mathrm{p}=.559 \mathrm{~ns}$ \\
\hline \multirow{2}{*}{ INT } & Male & $11.613 \pm 5.499$ & .681 \\
\cline { 2 - 4 } & Female & $11.038 \pm 5.179$ & $\mathrm{p}=.497 \mathrm{~ns}$ \\
\hline
\end{tabular}

ns: not significant

\section{DISCUSSION}

Life satisfaction is an important aspect in the psychosocial study of aging and is a key concept in successful aging. Research reports on quality of life shows that the life satisfaction is strongly related to sociodemographic and psycho-social variables. In this study, the elderly living with their family members had a better social relationship compared to those living in old age homes. It could probably be due to lesser privacy, restricted mobility, depression and loneliness felt by the inmates of free homes. Elders living with their families probably feel less depressed, engage themselves in community activities and make new social contacts.

Studies have shown the importance of social relationships and support as a protective factor for cognitive inabilities in the elderly, which helps them to live independently within their families and society. 
This helps in their psychological well-being. A study carried out among elderly in Denmark demonstrate that key factors in maintaining functionality in elderly persons are the diversity of social relationships and participation in social activities (14). Systematic reviews also concluded that there is an inverse relation between the number of social contacts and physical activity and psychological incapacity.

Social isolation has been a concern on health research in geriatric population. In an environment which is constantly changing, the older generation are facing several challenges to remain socially connected. Retirement leads to diminished social roles and physical morbidities may limit the participation in social activities. Previous studies shows that the elderly who experience social isolation have a greater risk for morbidity and mortality, and suffer from depression. The present study showed that social participation was better among those living with their families compared to those living in old age homes. Further, elders living in the old age homes had a better personal and intimate relationship compared to those living with their families. The better social relations among the family dwellers might probably be due to the support from the dear ones and constant interaction and freedom to express their feelings. This reinforces the need to preserve the traditional joint family system where the young and old can understand each other and mutually interact. Our study finding is in consistent with the previous report which focuses the social functioning as a domain of successful ageing. Social relationships enable the older individuals to gain emotional support, instrumental support to perform the daily activities, materialistic support to solve practical problems and new information to adjust and understand the ever-changing society. A regular involvement in physical and social activities would help the elderly to preserve their physical and cognitive abilities. This can delay the onset of social dependence associated with ageing. Therefore, it is important that we must understand the aspect of isolation which may pose health risks for older individuals in particular. Combined efforts from the government, private organizations and individuals must be organized to solve the problems resulting from the greying society which can help in optimizing the ability of older people to successfully meet the challenges of aging.

Gender differences is becoming an issue in the aged not just because a greater number of women are surviving into old age, but also because they are vulnerable in several ways and are devoid of proper social support. In the present study, the elderly women had a lesser social relationship than elderly men. Previous studies also showed the supportive evidence of poor mental health-related quality of life among the elderly women due to the lack of support from their near and dear ones (15).
A study conducted in Uttarakhand showed that the mean $( \pm \mathrm{SD})$ of transformed total QoL score (TTS) was $57.76( \pm 10.97)(16)$. The highest score was observed in facet $\mathrm{V}$ (death and dying) and the lowest was for intimacy. Another similar study done in Uttar Pradesh, the mean scores of QoL domains was maximum in death and dying (83.20), followed by sensory ability (62.99). The lowest mean score was seen intimacy domain (22.80) (17). There was no significant difference in dead and dying domain between old age homes and families or elderly men and women in this study. Intimacy domain was not significant between men and women but is more among those living with their family members than among those living in old age homes.

A study conducted in Jharkhand showed that the mean score of 'social health' of elderly people living with their family (2.82) was better than those living in old age home (1.55), which is similar to our study (18). A study done in Andhra Pradesh showed the quality of life in social domains were better in elderly living in community than OAHs, whereas in environmental domain was better in elderly living in OAHs were better than elderly in community (19). Our study did not show a significant difference in environment and social domain.

In Karnataka, a study in urban Bangalore District revealed that elderly living in OAHs showed a higher score QoL than non-institutional setup and that there was a significant gender among them in physical, psychological, level of independence, environment and social relationship domains of QoL (20). The results of another study in Udupi showed the maximum score in environmental domain $(60.46 \pm 10.14)$ and minimum in social domain (34.66 \pm 14.87$)$; there were no significant difference when gender and different age groups were considered (21). But our study showed significant difference in social relationship. A study in urban areas of Mangalore showed that the average QoL was observed among $74.3 \%$ of the elderly (mean score: 80.28-91.1), but it did not consider the elderly living in old age homes (22).

A limitation of this study is that the sample population is limited to urban areas in Mangalore and needs to be extended to the rural areas.

There are only a few studies on assessment of the quality of life among the elderly residing in old age homes and with family in India. The main strength of our study is that this study compares and signifies the extent of social relationship and social participation among the elderly men and women based on their place of residence. This study emphasizes the need to protect the rights of the elderly by focusing on age related issues, by implementation of gender-just policies for protection, both economic and social, at times of morbidity in old age. However, India is not adequately equipped to adjust to the changing 
traditional value system and care of the elderly. The National Rural Health Mission of India aims at transforming primary health services from curative to preventive services, especially to the elderly population. It is high time that the health care system plan policies, aim to improve the quality of life and take necessary actions for the weak elderly population especially those living in old age homes in elderly. Thus, an effective health perspective and its maintenance can ease the problem at individual level. Old age home can never replace home. Ageing must be accepted as an indispensable part of human life cycle and the world must encourage positive attitudes towards the weaker elder population.

Social isolation is the main obstacle towards loneliness among elderly. The old must be given the right to live free in dignity. There is a growing need for interventions among the elderly populations to meet their needs. Further research is needed to explore the problems faced by the elderly.

\section{CONCLUSION}

The elderly persons living with their family had a better social relationship and social participation than those living at old age homes. The elderly at old age homes had a better personal and intimate relationship than those living with their family. The elderly men had a better social relationship compared to elderly women. The elderly population requires urgent attention. It is high time we draw our attention to the problems lying ahead and recommend solutions for better reformations in the public sector regarding health care, home facilities and gender quality issues in order to provide better life satisfaction in old age. The community we are living in must recognize the needs of the elderly and implement better policies for the betterment of the elderly. Hence, as social beings, each and every one of us has the responsibility to take care of our older generation, who helped to mold us into the individual we are today.

\section{ACKNOWLEDGEMENT}

All the authors are grateful to the management staff of old age homes in Mangalore for their help and support extended towards this study.

\section{CONFLICT OF INTEREST}

The authors declare no conflict of interest.

\section{REFERENCES}

1. Areeckal, A. S., Arunkumar, N., Pai, S. R. Comparison of Body Mass Index in relation to their place of residence among elderly population in Mangalore. International Journal of Biomedical Research. 2015; 6(2): 101-103.

2. INDIA P. Census of India 2011 Provisional Population Totals. New Delhi: Office of the Registrar General and Census Commissioner; 2011.

3. Jeyalakshmi, S., Chakrabarti, S., Gupta, N. Situation analysis of the elderly in India. Central Statistics Office, Ministry of Statistics and Programme Implementation, Government of India document. $2011 \mathrm{Jul} 4$.
4. Sivaraju, S., Alam, M., Gangadharan, K. R., Syamala, T. V. S., Gupta, N. Caring for Our Elders: Early Responses-India Ageing Report. United Nations Population Fund. 2017: 1-1.

5. India Population (2020) - Worldometers [Internet]. Worldometers.info. 2020 [cited 28 August 2020]. Available from:https://www.worldometers.info/demographics/indiademographics/\#life-exp

6. Age dependency ratio, old (\% of working-age population) India. World Bank data. [Accessed 2020 Aug 28] Available from:https://data.worldbank.org/indicator/SP.POP.DPND.O L?end=2019\&locations $=I N \&$ start=2001.

7. Elderly in India-Profile and Programmes 2016. Central Statistics Office. Ministry of Statistics and Programme Implementation. Government of India. Available at: http://www.mospi.gov.in/sites/default/files/publication_repo rts/ElderlyinIndia_2016.pdf. Accessed on 28th August 2020.

8. HelpAge India. Directory of old age home in India. Help Age India, Regional Office, Delhi, India, 2002.

9. Enkvist, A., Ekström, H., Elmståhl, S. What factors affect life satisfaction (LS) among the oldest-old?. Archives of gerontology and geriatrics. $2012 \mathrm{Jan}$; 54(1): 140-145.

10. Solvason, C., Kington, A. Collaborations: providing emotional support to senior leaders. Journal of Professional Capital and Community. 2019; 5(1): 1-14.

11. Wang, G., Hu, M., Xiao, S.Y., Zhou, L. Loneliness and depression among rural empty-nest elderly adults in Liuyang, China: a cross-sectional study. BMJ open. 2017 Oct ; 7(10): $\mathrm{e} 016091$.

12. The WHOQOL Group. Development of the World Health Organization WHOQOL-BREF Quality of Life Assessment. Psychol Med. 1998; 28: 551-558.

13. Power, M., Quinn, K., Schmidt, S. WHOQOL-OLD Group. Development of the WHOQOL-OLD module. Qual Life Res. 2005 Dec; 14(10): 2197-2214.

14. Avlund, K., Lund, R., Holstein, B.E., Due, P. Social relations as determinant of onset of disability in aging. Arch GerontolGeriatr. 2004 Jan-Feb; 38(1): 85-99.

15. Lodha, P., De Sousa, A. Geriatric mental health: The challenges for India. J GeriatrMent Health. 2018; 5: 16-29.

16. Kritika, Kakkar, R., Aggarwal, P., Semwal, J. Quality of Life (QOL) among the Elderly in Rural Dehradun. Indian JCommunity Health. 2017 Mar; 29(1): 39-45.

17. Bansal, P., Dixit, A., Jain, P., Gupta, S., Bajpai, P., Mehra, J. Assessment of quality of life among elderly population of rural areas of Etawah district: a cross sectional study. Int J Community Med Public Health. 2019; 6(5): 1965-1969.

18. Panday, R., Kiran, M., Srivastava, P., Kumar, S. A study on quality of life between elderly people living in old age home and within family setup. Open J Psychiatry Allied Sci. 2015; 6: 127.

19. Chandrika, S., Radhakumari, P., Devi Madhavi, B. Quality of life of elderly residing in old age homes and community in Vishapatnam city. J Dent Med Sci. 2015; 14: 27-31.

20. Devi, L., Roopa, K. S. Quality of life of elderly men and women in institutional and noninstitutional settings in urban Bangalore district. Research Journal of Family, Community and Consumer Sciences. 2013 May; 1(13): 7-13.

21. Asadullah, M., Kuvalekar, K., Katarki, B., Malamardi, S., Khadka, S., Wagle, S. A study on morbidity profile and quality of life of inmates in old age homes in Udupi district, Karnataka, India. Int J Basic Appl Med Sci. 2012; 2(3): 9197.

22. Devraj, S., D’Mello, M. K. Determinants of quality of life among the elderly population in urban areas of Mangalore, Karnataka. Journal of Geriatric Mental Health. 2019 Jul; 6(2): 94. 